\title{
Métodos para avaliação da atividade antimicrobiana e determinação da concentração mínima inibitória (CMI) de plantas medicinais
}

\author{
Elissa A. Ostrosky, ${ }^{1}$ Miriam K. Mizumoto, ${ }^{1}$ Marcos E. L. Lima, ${ }^{2}$ Telma M. Kaneko, ${ }^{1}$ \\ Suzana O. Nishikawa, ${ }^{1}$ Beatriz R. Freitas* ${ }^{* 1}$ \\ ${ }^{1}$ Universidade de São Paulo, Faculdade de Ciências Farmacêuticas, Avenida Professor Lineu Prestes, 580, \\ 05508-900 São Paulo-SP, Brasil, \\ ${ }^{2}$ Universidade de São Paulo, Instituto de Química, Avenida Professor Lineu Prestes, 748, 05508-900 \\ São Paulo-SP, Brasil
}

\begin{abstract}
RESUMO: Várias pesquisas vêm sendo desenvolvidas e direcionadas no descobrimento de novos agentes antimicrobianos provenientes de extratos de plantas e outros produtos naturais, para serem aplicados em produtos farmacêuticos e cosméticos. Atualmente, existem vários métodos para avaliar a atividade antibacteriana e antifúngica dos extratos vegetais. Os mais conhecidos incluem método de difusão em ágar, método de macrodiluição e microdiluição. A proposta dessa revisão é apresentar diferentes métodos comumente utilizados na pesquisa de novos agentes antimicrobianos, provenientes de extratos vegetais, e elucidar os principais fatores interferentes. Dessa maneira, contribuir como fonte de pesquisa para o desenvolvimento de futuros trabalhos relacionado ao estudo de atividade antimicrobiana de produtos naturais.
\end{abstract}

Unitermos: Atividade antimicrobiana, difusão em ágar, microdiluição, macrodiluição, concentração mínima inibitória (CMI), extrato vegetais.

\begin{abstract}
Methods for evaluation of the antimicrobial activity and determination of minimum inhibitory concentration (MIC) of plant extracts". Several researches have been developed to search for new antimicrobial agents from extracts of plants and other natural products to be used in pharmaceutical and cosmetic products. Nowadays there are many methods to evaluate the antibacterial and antifungal activity of the plant extracts. The most known assays have been based on diffusion in agar; and micro and macrodilution methods. The purpose of this review is to describe the different methods commonly used for the determination of new antimicrobial agents from the plants extracts and elucidate the main interference factors. Moreover, this contributes as research source for future development of investigations related to the study of antimicrobial activity from natural products.
\end{abstract}

Keywords: Antimicrobial activity, agar diffusion, microdilution, macrodilution, minimal inhibitory concentration (MIC), plant extract.

\section{INTRODUÇÃO}

A atividade antimicrobiana de extratos vegetais é avaliada através da determinação de uma pequena quantidade da substância necessária para inibir o crescimento do microrganismo-teste; esse valor é conhecido como Concentração Mínima Inibitória (CMI). Um aspecto bastante relevante na determinação da CMI de extratos vegetais é a preocupação em relação aos aspectos toxicológicos, microbiológicos e legais pertinentes aos compostos naturais ou suas combinações (Pinto et al., 2003).

A pesquisa de novos agentes antimicrobianos se faz necessária devido ao surgimento de microrganismos resistentes e de infecções oportunistas fatais, associadas a AIDS, quimioterapia antineoplásica e transplantes (Penna et al., 2001). O estudo de agentes antimicrobianos tem grande abrangência, sendo ponto crucial em vários setores do campo farmacêutico e cosmético. Outro ponto a ser ressaltado é a utilização desse estudo como primeiro screening na descoberta da atividade farmacológica de novos agentes, sendo de extrema importância, principalmente em um país como o Brasil que oferece uma imensa biodiversidade. Desta forma, tais pesquisas podem contribuir significativamente no desenvolvimento do campo da saúde em nível mundial, encontrando substâncias mais eficazes e menos tóxicas na corrida contra a resistência e o surgimento de microrganismos patogênicos (Meng et al., 2000; Ho et al., 2001; Michelin et al., 2005; Leitão et al., 2006; Lima et al., 2006b; Barbosa-Filho et al., 2007; Saúde-Guimarães \& Faria, 2007).

Atualmente, existem vários métodos para avaliar a atividade antibacteriana e antifúngica dos extratos vegetais. Os mais conhecidos incluem método de difusão em ágar, método de macrodiluição e microdiluição. Para 
determinar a CMI ou a Concentração Mínima Bactericida (CMB) de extratos ativos de plantas, tem-se utilizado um método sensível de microdiluição desenvolvido por Eloff em 1998.

As variações referentes à determinação da CMI (Concentração Mínima Inibitória) de extratos de plantas podem ser atribuídas a vários fatores. Dentre eles podemos citar a técnica aplicada, o microrganismo e a cepa utilizada no teste, à origem da planta, a época da coleta, se os extratos foram preparados a partir de plantas frescas ou secas e a quantidade de extrato testada. Assim, não existe método padronizado para expressar os resultados de testes antimicrobianos de produtos naturais (Fennel et al., 2004).

A proposta dessa revisão é descrever os diferentes métodos comumente utilizados na pesquisa de novos agentes antimicrobianos provenientes de extratos vegetais, bem como seus fatores interferentes.

\section{Métodos de difusão}

O teste de difusão em ágar, também chamado de difusão em placas, é um método físico, no qual um microrganismo é desafiado contra uma substância biologicamente ativa em meio de cultura sólido e relaciona o tamanho da zona de inibição de crescimento do microrganismo desafiado com a concentração da substância ensaiada (Pinto et al., 2003).

A aplicação do método de difusão se limita a microrganismos de crescimento rápido, sendo eles aeróbios ou aeróbios facultativos. A avaliação é comparativa frente a um padrão biológico de referência (controle positivo) e a zona ou o halo de inibição de crescimento é medida partindo-se da circunferência do disco ou poço, até a margem onde há crescimento de microrganismos (Barry \& Thornsberry, 1991). De acordo com a dimensão do halo os microrganismos podem ser classificados como: sensíveis, quando o diâmetro da zona de inibição é maior ou não mais do que $3 \mathrm{~mm}$ menos que o controle positivo; moderadamente sensíveis, halo maior que $2 \mathrm{~mm}$, mas menor que o controle positivo de mais de $3 \mathrm{~mm}$; e resistentes, diâmetro igual ou menor que $2 \mathrm{~mm}$. Como controle positivo, emprega-se um quimioterápico padrão, e como controle negativo o solvente utilizado para a dissolução dos extratos (Karaman et al., 2003; Springfield et al., 2003).

As condições de incubação recomendadas são temperatura de $35-37{ }^{\circ} \mathrm{C}$ para bactérias durante 24 a 48 horas e para fungos de 25 a $27^{\circ} \mathrm{C}$ por 48 a 72 horas (Carvalho et al., 2002; Chandrasekaram \& Venkatesalu, 2004; Karaman et al., 2003; Moody et al., 2004; Springfield et al., 2003; Ayres et al., 2008). Como variação do método, Rabanal et al. (2002) incubaram as placas de Petri por $14 \mathrm{~h}$ à temperatura de $37^{\circ} \mathrm{C}$ para bactérias e de 28 a $30{ }^{\circ} \mathrm{C}$ para fungos.

As técnicas de aplicação da substância antimicrobiana no método de difusão são por meio de disco, cilindros de aço inoxidável ou vidro e perfuração em ágar (Pinto et al., 2003).

\section{Teste de difusão em disco}

O teste de difusão em disco é aceito pelo FDA (Food and Drug Administration) e estabelecido como padrão pelo NCCLS (National Committe for Clinical Laboratory Standards) (Barry \& Thornsberry, 1991).

O teste de difusão em disco sugerido por Rabanal et al. (2002) e por Karaman et al. (2003) consiste na aplicação de $10 \mu \mathrm{L}$ da solução de agente antimicrobiano em discos de papel de filtro de $6 \mathrm{~mm}$ de diâmetro, nas diferentes concentrações a serem testadas variando de 31,25 a $500 \mu \mathrm{g} / \mathrm{mL}$. Como variação do método, Carvalho et al. (2002); Chandrasekaran \& Venkatesalu (2004) aplicaram $20 \mu \mathrm{L}$ de extrato hidroalcoólico de Psidium guajava L. e extratos metanólico e aquoso de Syzygium jambolanum, respectivamente, nos discos de papel, com concentrações de 500 a $1000 \mu \mathrm{g} / \mathrm{mL}$. Springfield et al. (2003) testaram diferentes extratos obtidos de 2 espécies de Carpobrotus aplicando $50 \mu \mathrm{L}$ das soluções em discos de papel de filtro de $9 \mathrm{~mm}$. Penna et al. (2001) verificaram a atividade antimicrobiana de 3 extratos de diferentes plantas da flora argentina pelo método de difusão em ágar. Discos de papel de $5,5 \mathrm{~mm}$ foram impregnados com $0,25 \mathrm{mg}$ do extrato seco dissolvido em $10 \mu \mathrm{L}$ do solvente correspondente.

Rabanal et al. (2002) utilizaram disco impregnado com DMSO (dimetilsulfóxido) para o controle negativo, e como controle positivo foi utilizado cloranfenicol (30 $\mu \mathrm{g})$ para bactérias e anfotericina $\mathrm{B}(100 \mu \mathrm{g})$ para fungos. Springfield et al. (2003) utilizaram ciprofloxacino (40 $\mu \mathrm{L})$ para controle positivo de bactérias e anfotericina $\mathrm{B}$ $(25 \mu \mathrm{L})$ para fungos.

No estudo conduzido por Tadeg et al. (2005), extratos hidroalcoólicos de 8 espécies de plantas medicinais usadas no tratamento de desordens de pele foram avaliados quanto à atividade antimicrobiana em relação a bactérias e fungos conhecidos por causarem diferentes tipos de infecções cutâneas. A atividade antimicrobiana foi determinada utilizando o método de difusão em ágar nas concentrações de 100,50 e $25 \mathrm{mg} /$ $\mathrm{mL}$ para os extratos brutos e 25 e $5 \mathrm{mg} / \mathrm{mL}$ para as frações. Como controle negativo foram utilizados metanol, clorofórmio e água destilada e como controle positivo gentamicina e cetoconazol. Obtendo como os melhores resultados as frações clorofórmio e éter de petróleo da Lippia adoensis contra bactérias e Olinia rachetiana contra fungos.

Voravunthikunchai et al. (2004) determinaram o CMI de extratos etanólicos e aquosos de plantas medicinais que produziam zonas de inibição utilizando o método de difusão em ágar. Amicacina, ampicilina, gentamicina, kanamicina e tetraciclina como amostras de referência, e $1 \mu \mathrm{L}$ de cada cultura de bactérias foi colocado em MHA (Mueller Hinton Agar) juntamente 
com os extratos de plantas medicinais. Após incubação por $18 \mathrm{~h}$ a $35^{\circ} \mathrm{C}$, determinou-se a mínima concentração capaz de produzir a completa supressão das colônias.

A metodologia consiste em colocar os discos sobre o meio de cultura sólido previamente inoculado em placas de Petri com diferentes cargas microbianas, $10^{8}$ UFC (Unidade Formadora de colônia) $/ \mathrm{mL}$ para bactérias, $10^{6} \mathrm{UFC} / \mathrm{mL}$ para leveduras e $10^{4}$ para esporos/ $\mathrm{mL}$ (Chattopadhyay et al., 2002; Karaman et al., 2003). A disposição dos discos deve ser tal que sua distância até a lateral da placa seja maior que $15 \mathrm{~mm}$ e de modo a não sobrepor as zonas de inibição. $\mathrm{O}$ pH do meio de cultura deve estar entre 7,2 e 7,4, e a profundidade recomendada é de aproximadamente $4 \mathrm{~mm}$ (Barry \& Thornsberry, 1991).

\section{Cilindros de aço inoxidável}

Esta técnica de aplicação envolve cilindros de aço inoxidável no meio de cultura solidificado já inoculado e a adição da solução em estudo nos cilindros. Coelho de Souza et al. (2004) aplicaram $200 \mu \mathrm{L}$ dos extratos de plantas medicinais comumente utilizadas no Rio Grande do Sul, Brasil. Como controle positivo para bactérias foi aplicado cloranfenicol $(40 \mu \mathrm{g} / \mathrm{mL}, 200 \mu \mathrm{L})$, e para fungos, nistatina $(30 \mathrm{mg} / \mathrm{mL}, 200 \mu \mathrm{L})$, metanol $(200 \mu \mathrm{L})$ e água $(200 \mu \mathrm{L})$ foram utilizados como controles negativos.

Lopes et al. (2006) empregaram o método de difusão em ágar, utilizando cilindros. Foi empregada uma suspensão de $S$. aureus ATCC 6538 na concentração de $10^{8} \mathrm{UFC} / \mathrm{mL}$, desafiando $200 \mu \mathrm{L}$ de extratos glicólicos de Physalis angulata $\mathrm{L}$ em diferentes concentrações e como controle positivo uma curva padrão de ampicilina.

\section{Perfuração em agar}

$\mathrm{Na}$ técnica de perfuração em ágar, a remoção do meio de cultura sólido é realizada com auxílio de cilindros de 6-8 $\mathrm{mm}$ de diâmetro para a formação de poços, nos quais é possível aplicação das substâncias a serem analisadas. Moody et al. (2004) preencheram os poços com $60 \mu \mathrm{L}$ dos extratos de Aloe vera e Ageratum conyzoides para verificar a atividade antimicrobiana de sopas medicinais utilizadas na Nigéria. Como controle positivo foi aplicado estreptomicina $(100,25$ e 6,25 $\mu \mathrm{g} / \mathrm{mL})$ para bactérias e tioconazol $(100,25$ e $6,25 \mu \mathrm{g} /$ $\mathrm{mL}$ ) para fungos. $\mathrm{O}$ controle negativo constituiu de metanol:água $50 \%(\mathrm{v} / \mathrm{v})$, veículo utilizado para dissolver os extratos secos nas diferentes concentrações.

Okeke et al. (2001) avaliaram a atividade antibacteriana de extratos obtidos da raiz de Landolphia owerrience. Os poços de $6 \mathrm{~mm}$ de diâmetro foram confeccionados em placa previamente inoculada com uma suspensão microbiana $5 \times 10^{5} \mathrm{UFC} / \mathrm{mL}$, posteriormente preenchidos com $100 \mu \mathrm{L}$ dos extratos dissolvidos em DMSO. A gentamicina $(8$ e $16 \mu \mathrm{g} / \mathrm{mL})$ foi utilizada como controle positivo e uma solução de DMSO como controle

negativo.

Lima et al. (2006b) verificaram a atividade antifúngica de óleos essenciais sobre diferentes espécies de Candida, utilizando o método de difusão em meio sólido, aplicando a técnica de perfuração feita através de cânulas de vidro, obtendo poços de $6 \mathrm{~mm}$ de diâmetro. Utilizaram alíquotas de $50 \mu \mathrm{L}$ da solução dos óleos essenciais em diferentes concentrações e inoculo de $10^{6} \mathrm{UFC} / \mathrm{mL}$. O sistema foi incubado por $24-48 \mathrm{~h}$ por $35^{\circ} \mathrm{C}$. A CMI foi considerada aquela concentração do óleo essencial capaz de desenvolver halo de inibição do crescimento fúngico maior ou igual a $10 \mathrm{~mm}$ de diâmetro. Como controle negativo foi empregado polissorbato, e como controle positivo o cetoconazol $(50 \mu \mathrm{g} / \mathrm{mL})$.

\section{Método de diluição em caldo}

O método de diluição em caldo considera a relação entre a proporção de crescimento do microrganismo desafiado no meio líquido e a concentração da substância ensaiada. A avaliação é comparada frente a um padrão biológico de referência. Entende-se por proporção a densidade da turbidez provocada pelo crescimento microbiano (Pinto et al., 2003).

$\mathrm{O}$ método fornece resultados quantitativos e não é influenciado pela velocidade de crescimento dos microrganismos. Sua desvantagem é a dificuldade na detecção de contaminação no caso de teste de materiais clínicos. Como controle positivo, utiliza-se o caldo com o quimioterápico padrão com a suspensão padronizada de microrganismo em teste, e como controle negativo o meio de cultura com o solvente usado para dissolução da amostra e a suspensão microbiana (Sahm \&Washington II, 1991). Duas metodologias podem ser empregadas: macro e microdiluição.

\section{Macrodiluição}

A macrodiluição envolve testes em tubos de ensaio, com volume de meio de cultura variando de 1 e 10 $\mathrm{mL}$. Por ser laborioso, consumir muito tempo, requerer muito espaço no laboratório e gerar grande quantidade de resíduos é usado pequeno número de réplicas ( $\mathrm{Sahm} \mathrm{\&}$ Washington II, 1991; Zgoda \& Porter, 2001).

\section{Microdiluição}

A microdiluição utiliza microplacas com 96 poços, com volume de meio de cultura entre 0,1 e 0,2 $\mathrm{mL}$. Eloff (1998) utilizou a técnica de diluição em microplacas para verificar a atividade antimicrobiana em extratos vegetais e observou inconvenientes na técnica, tais como células de alguns microrganismos que se aderiam à base do poço, enquanto as de outros permaneciam em suspensão. Ainda, compostos presentes em alguns extratos precipitavam, e a coloração verde da clorofila em concentração muito alta interferia na análise. 
Todavia, concluiu que o método de microplacas é barato, tem reprodutibilidade, é 30 vezes mais sensível que outros métodos usados na literatura, requerem pequena quantidade de amostra, pode ser usado para grande número de amostras e deixa um registro permanente.

Zgoda \& Porter (2001) utilizaram extratos orgânicos das plantas Lemna minor e Ilex cornuta para desenvolver uma técnica de microdiluição para a pesquisa de novos compostos com atividade antimicrobiana contra bactérias e fungos. Para cada microplaca foi usado um controle negativo (água, meio de cultura e 2,5\% DMSO), controle de crescimento (água, meio de cultura, 2,5\% DMSO e inóculo), controle positivo (água, meio de cultura, inóculo, 2,5\% DMSO e antibiótico). A inoculação sugerida foi a utilização de $95 \mu \mathrm{L}$ de água estéril, $5 \mu \mathrm{L}$ de extrato dissolvido em DMSO, $80 \mu \mathrm{L}$ do meio apropriado e $20 \mu \mathrm{L}$ de inóculo. Em teste prévio observou-se que concentrações maiores que 2,5\% DMSO nos poços inibia o crescimento de Cryptococcus albidus. As leituras foram feitas a $750 \mathrm{~nm}$ num espectrofotômetro, leitor de microplacas, após a agitação dos poços para ressuspender as células aderidas no fundo com uma pipeta multicanal.

Simié et al. (2004) estudaram a atividade antifúngica de alguns óleos essenciais de Lauraceae determinando a CMI em microplacas de 96 poços. Os óleos essenciais investigados foram dissolvidos em MS (Malt Agar) inoculado com fungos. As microplacas foram incubadas a $28{ }^{\circ} \mathrm{C}$ por 72 horas. As menores concentrações sem crescimento aparente foram definidas como as concentrações que inibem completamente o crescimento de fungos.

Karaman et al. (2003) utilizaram a técnica para verificar a atividade antimicrobiana do extrato metanólico de Juniperus oxycedrus dissolvido em DMSO $10 \%$, concentração de solvente que não inibe o crescimento dos microrganismos. A técnica descrita por Zogda \& Porter (2001) foi adaptada, dispensando-se 95 $\mu \mathrm{L}$ de caldo nutriente e $5 \mu \mathrm{L}$ de inóculo em cada poço. No primeiro foi então adicionado $100 \mu \mathrm{L}$ de extrato de $J$. oxycedrus preparado incialmente na concentração de 500 $\mu \mathrm{g} / \mathrm{mL}$. Fez-se então uma diluição seriada nos 6 poços consecutivos, retirando-se $100 \mu \mathrm{L}$ do poço de maior concentração, resultando na diluição de até $7,8 \mu \mathrm{g} / \mathrm{mL}$. No último poço não se adicionou o inóculo e o extrato, a fim de se ter um controle negativo. $\mathrm{O}$ crescimento microbiano foi determinado por leitura no espectrofotômetro a 600 nm.

Khan \& Katiyar (2000) testaram a atividade antifúngica do extrato de alho (Allium sativum) em microplacas, aplicando $270 \mu \mathrm{L}$ de meio SDB por poço. $30 \mu \mathrm{L}$ do extrato foram adicionados nos primeiros poços e a partir deles foram feitas as diluições seriadas. Em seguida, foi colocado o inóculo de $10^{4} \mathrm{UFC}$ em cada poço. Controles foram submetidos às mesmas condições laboratoriais. A leitura foi feita após 48-72 h em leitor de Elisa a $492 \mathrm{~nm}$.

Foram testados os frutos de espécies

pertencentes à família Arecaceae (Palmae), empregando a metodologia de microdiluição em caldo. Observou-se que de uma maneira geral, a atividade antimicrobiana aumentou com a diminuição da polaridade dos extratos de Syagrus oleracea, sendo que os extratos avaliados foram efetivos contra cepas Gram negativas e Gram positivas, provavelmente devido à presença de ácidos graxos (Silveira et al., 2005).

\section{Fatores que interferem nos métodos}

Diversos são os fatores que afetam a suscetibilidade do método de difusão e de diluição, há assim, a necessidade do conhecimento das condições experimentais e padronização rigorosa na execução do teste.

Os aspectos importantes a serem considerados são:

\section{Meios de cultura}

Os meios de cultura devem proporcionar um crescimento adequado dos organismos a serem desafiados e não conter substâncias antagônicas à atividade antimicrobiana em estudo. No método de difusão a concentração do ágar e a sua origem podem influenciar os resultados dos ensaios (Pinto et al., 2003). Entre os meios de cultura utilizados para teste de susceptibilidade de bactérias, o Müller-Hinton é o mais citado, outros meios bastante utilizados são o de caseína soja (TSA e TSB) e o meio líquido Luria-Bertani para bactérias. Em relação aos fungos são utilizados os meios ágar e caldo sabourand dextrose (SDA e SDB), ágar batata dextrose (PDA) e caldo de levedura (Barry \& Thonrsberry, 1991; Carvalho, et al., 2002; Chandrasekaram \& Venkatesalu, 2004; Chattopadhyay et al., 2002; Cortez et al., 2002; Eloff, 1998; Rabanal et al., 2002; Sahm \& Washington II, 1991; Scazzocchio et al., 2001; Coelho de Souza et al., 2004; Irobi \& Adedayo, 1999; Karaman et al., 2003; Khan \& Katiyar, 2000; Zgoda \& Porter, 2001).

Segundo Barry \& Thornsberry (1991) há substâncias no meio de cultura que influenciam a susceptibilidade do teste, a timidina antagoniza a atividade de sulfonamidas e trimetroprinas, conduzindo a um resultado falso de resistência a tais agentes. Se o meio contiver altas concentrações de timidina, pode-se adicionar sangue lisado de cavalo ou timidina fosforilada para remover a timidina livre. O cátion monovalente $\mathrm{Na}^{+}$aumenta a atividade de bacitracina, ácido fusídico e novobiocina contra Staphylococcus spp e da penicilina contra Proteus spp. Cátions bivalentes tais como $\mathrm{Mg}^{2+}$ e $\mathrm{Ca}^{2+}$ reduzem a atividade de aminoglicosídeos e polimixinas contra Pseudomonas spp e da tetraciclina contra uma série de organismos.

pH 
$\mathrm{O} \mathrm{pH}$ do sistema deve ser compatível com o crescimento microbiano, com a atividade e a estabilidade das substâncias testadas. O aumento da acidez do meio diminui a atividade antibacteriana de substâncias básicas como a estreptomicina, e por outro lado, provoca o aumento da atividade de substâncias ácidas como a penicilina (Pinto et al., 2003).

Barry \& Thornsberry (1991) afirmam que a atmosfera com concentração de $\mathrm{CO}_{2}$ elevada, deve ser evitada, já que altera o $\mathrm{pH}$ da superfície, sendo então capaz de afetar a atividade antimicrobiana de alguns agentes.

Li-Chang et al. (2005) avaliaram o efeito do $\mathrm{pH}$ (5-9) na atividade antimicrobiana do extrato etanólico de própolis inoculado com o microrganismo teste e incubado a $37{ }^{\circ} \mathrm{C}$ por $9 \mathrm{~h}$. O extrato exerceu um efeito bactericida em $S$. aureus, após 1,5 e $3 \mathrm{~h}$ de cultivo em $\mathrm{pH}$ 5 e 6 respectivamente.

\section{Disponibilidade de oxigênio}

Conforme o metabolismo do microrganismo desafiante, aeróbicos, anaeróbicos ou facultativos, as condições de disponibilidade desse gás podem influenciar na sua multiplicação. Nos trabalhos desenvolvidos para a determinação da atividade da estreptomicina utilizando Staphylococcus aureus, por diluição em tubos, verificouse que houve pouca influência da disponibilidade de oxigênio (Pinto et al., 2003).

\section{Inóculo}

A susceptibilidade dos agentes antimicrobianos é dependente da quantidade do inóculo. A padronização desse se faz, portanto, necessária e a quantidade inoculada deverá ser estabelecida para cada método desenvolvido. No teste de suscetibilidade de meticilina contra Staphylococcus, esse padrão deve ser de $10^{6} \mathrm{UFC} /$ $\mathrm{mL}$. Para os testes de diluição em caldo, o padrão é de $10^{5} \mathrm{UFC} / \mathrm{mL}$ no início do período de incubação (Sahm \& Washington II, 1991).

Segundo recomendação de Barry \& Thornsberry (1991); Sahm \& Washington II (1991), a preparação do inóculo nos métodos de diluição e difusão deve ser feita a partir de 4 ou 5 colônias da cultura do microrganismo desafiado para evitar selecionar uma cepa variante atípica. Após o crescimento das colônias por $16 \mathrm{~h}$ em caldo nutriente, os microrganismos devem ser diluídos em água destilada para a concentração de $10^{7} \mathrm{UFC} / \mathrm{mL}$. O padrão de leitura 0,5 na escala McFarland fornece densidade de aproximadamente $10^{8} \mathrm{UFC} / \mathrm{mL}$. Alternativamente, o inóculo pode ser ajustado fotometricamente ou por diluição padronizada do caldo nutriente, se a densidade de tais culturas for razoavelmente constante. As placas devem ser inoculadas em até 30 minutos após a padronização do inóculo, para que a densidade celular não esteja alterada.

Para o teste de microdiluição, Rabanal et al.
(2002) utilizaram inóculo de $5 \mu \mathrm{L}$, equivalente a $10^{5}$ células por $\mu \mathrm{L}$ em cada poço.

\section{Condições de incubação}

A incubação dos microrganismos deve ser feita a $35-37{ }^{\circ} \mathrm{C}$ para o crescimento de bactérias e 25 a 27 ${ }^{\circ} \mathrm{C}$ para fungos. No método de diluição, as condições de crescimento dos microrganismos nos tubos devem ser semelhantes, propiciando-se a mesma temperatura e agitação. No método de difusão as placas devem ser incubadas com o cuidado de se manter a temperatura homogênea na estufa. Condições alternativas só devem ser utilizadas se forem essenciais para o crescimento do microrganismo em teste (Chandrasekaran \& Venkatesalu, 2004; Karaman et al., 2003; Springfield et al., 2003).

\section{Recursos utilizados para melhoria da leitura do diâmetro do halo no método de difusão em ágar}

A espessura e a uniformidade do ágar são essenciais para a boa resolução dos resultados. Deve-se controlar rigorosamente o volume de ágar transferido para a placa de Petri, e o meio de cultura deve ser distribuído de modo a evitar formação de estrias superficiais e bolhas. Quando ocorrem halos de pequenas dimensões, o recurso utilizado é a diminuição do volume do meio, o que leva a diminuição a espessura do meio na placa. A pré-incubação é utilizada quando se visa diminuir a dimensão do halo e a pré-difusão para aumentar a zona de inibição (Pinto et al., 2003).

\section{CONCLUSÃO}

Em um "screening" extensivo de plantas utilizadas na medicina tradicional, destaca-se os extratos vegetais com ação antimicrobiana, devido a sua importância no desenvolvimento e produção de produtos farmacêuticos e cosméticos. Através da análise dos artigos citados nessa revisão, concluímos que o método de diluição em agar é o mais utilizado, devido à simplicidade de execução e ao baixo custo. Já na determinação da CIM, o método da microdiluição, desenvolvido por Eloff em 1998, vem sendo bastante utilizado, principalmente devido à sua sensibilidade e quantidade mínima de reagentes, o que possibilita um maior número de réplicas, aumentando a confiabilidade dos resultados. Ressaltamos, finalmente, a importância de avaliar os fatores interferentes, estabelecendo parâmetros de acordo com a necessidade do método empregado para o determinado fim.

\section{AGRADECIMENTOS}

Os autores agradecem à CAPES e ao CNPq pelo apoio financeiro através da concessão de bolsa. 


\section{REFERÊNCIAS}

Ayres MCC, Brandão MS, Vieira-Júnior GM, Menor JCAS, Silva HB, Soares MJS, Chaves MH 2008. Atividade antibacteriana de plantas úteis e constituintes químicos da raiz de Copernicia prunifera. Rev Bras Farmacogn 18: 90-97.

Barbosa-Filho JM, Nascimento-Júnior FA, Tomaz ACA, Athayde-Filho PF, Silva MS, Cunha EVL, Souza MFV, Batista LM, Diniz MFFM 2007. Natural products with antileprotic activity. Rev Bras Farmacogn 17: 141-148.

Barry AL, Thornsberry C 1991. Susceptibility tests: Diffusion Test Procedures. In: Balows A, Hauser WJ, Hermann KL, Isenberg HD, Shamody HJ 1991. Manual of clinical microbiology. 5.ed. Washington, DC: American Society for Microbiology, p. 1117-1125.

Carvalho AAT, Sampaio MCC, Sampaio FC, Melo AFM, Sena KXFR, Chiappeta AA, Higino JS 2002. Atividade antimicrobiana in vitro de extratos hidroalcoólicos de Psidium guajava L. sobre bactérias gram-negativas. Acta Farm Bonaerense 21: 255-258.

Chandrasekaran M, Venkatesalu V 2004. Antibacterial and antifungal activity of Syzygium jambolanum seeds. $J$ Ethnopharmacol 91: 105-108.

Chattotadhyay D, Arunachalam G, Mandal AB, Sur TK, MandaL SC, Bhattacharya SK 2002. Antimicrobial and anti-inflammatory activity of folklore: Mallotus peltatus leaf extract. J Ethnopharmacol 82: 229-237.

Coelho de Souza G, Haas APS, Von Poser GL, Schapoval EES, Elisabetsky E 2004. Ethnopharmacological studies of antimicrobial remedies in the south of Brazil. $J$ Ethnopharmacol 90: 135-143.

Cortez DAG, Filho BAA, Nakamura CV, Filho BPD, Marston A, Hostettmann K 2002. Antibacterial activity of a biphenyl and xanthones from Kilmeyera coriacea. Pharm Biol 40: 485-489.

Eloff JN 1998. A sensitive and quick microplate method to determine the minimal inhibitory concentration of plant extracts for bacteria. Planta Med 64: 711-713.

Fennel CW, Lindsey KL, Mc Gaw LJ, Sparg SG, Stafford GI, Elgorashi EE, Grace OM, Van Staden J 2004. Review: Assessing African medicinal plants for efficacy and safety: Pharmacological screening and toxicology. $J$. Ethnopharmacol 94: 205-217.

Ho KY, Tsai CC, Huang HS, Chen CP, Lin TC, Lin CC 2001. Antimicrobial activity of tannin components from Vaccinium vitis-idaea L. J Pharm Pharmacol 53: 187-191.

Irobi ON, Adedayo O 1999. Antifungal activity of aqueous extract of dormant fruits of Hyphaene thebaica (Palmae). Pharm Biol 37: 114-117.

Karaman İ, Şahin F, Güllüce M, Öğütçü H, Şengül M, Adigüzel A 2003. Antimicrobial activity of aqueous and methanol extracts of Juniperus oxycedrus L. J Ethnopharmacol 85: 231-235.

Khan ZK, Katiyar R 2000. Potent antifungal activity of garlic (Allium sativum) against experimental murine disseminated cryptococcosis. Pharm Biol 38: 87-100.

Leitão SG, Castro O, Fonseca EM, Julião LS, Tavares ES, Leo RRT, Vieira RC, Oliveira DR, Leitão GG, Martino V, Sulsen V, Barbosa YAG, Pinheiro DPG, Silva PEA, Teixeira DF, Lourenço MCS 2006. Screening of Central and South American plant extracts for antimycobacterial activity by the Alamar Blue test. Rev Bras Farmacogn 16: 6-11.

Li-Chang L, Yue-Wen C, Cheng-Chun C 2005. Antibacterial activity of propolis against Staphylococus aureus. Int J Food Microbiol 102: 213-220.

Lima MRF, Ximenes CPA, Luna JS, Sant'Ana AEG 2006a. The antibiotic activity of some Brazilian medicinal plants. Rev Bras Farmacogn 16: 300-306.

Lima IO, Oliveira RAG, Lima EO, Farias NMP, Souza EL 2006b. Atividade antifúngica de óleos essenciais sobre espécies de Candida. Rev Bras Farmacogn 16: 197-201.

Lopes DCDXP, Freitas ZMF, Santos EP, Tomassini, TCB 2006. Atividades antimicrobiana e fototóxica de extratos de frutos e raízes de Physalis angulata L. Rev Bras Farmacogn 16: 206-210.

Meng JC, Zhu QX, Than RX 2000. New antimicrobial mono and sesquiterpenes from Soroseris hookeriana subsp. Erysimoides. Planta Med 66: 541-544.

Michelin DC, Moreschi PE, Lima AC, Nascimento GGF, Paganelli MO, Chaud MV 2005. Avaliação da atividade antimicrobiana de extratos vegetais. Rev Bras Farmacogn 15: 316-320.

Moody JO, Adebiyi OA, Adeniyi BA 2004. Do Aloe vera and Ageratum conyzoides enhance the anti-microbial activity of traditional medicinal soft soaps (Osedudu)? J Ethnopharmacol 92: 57-60.

Okeke MI, Iroegbu CU, Eze EN, Okoli AS, Esimone CO 2001. Evaluation of extracts of the root of Landolphia owerrience for antibacterial activity. JEthnopharmacol 78: 119-127.

Penna C, Marino S, Vivot E, Cruañes MC, Muñoz JD, Cruañes J, Ferraro G, Gutkind G, Martino V 2001. Antimicrobial activity of Argentine plants used in the treatment of infectious diseases. Isolation of active compounds from Sebastiania brasiliensis. J Ethnopharmacol 77: 37-40.

Pinto TJA, Kaneko TM, Ohara MT 2003. Controle Biológico de Qualidade de Produtos Farmacêuticos, Correlatos e Cosméticos. 2.ed. São Paulo: Atheneu Editora, 325 p.

Rabanal RM, Arias A, Prado B, Hernández-Pérez M, SánchezMateo CC 2002. Antimicrobial studies on three species of Hypericum from the Canary Islands. $J$ Ethnopharmacol 81: 287-292.

Sahm DF, Washington II JA 1991. Antibacterial susceptibility tests: Dilution methods. In: Balows, A.; Hauser, W.J.; Hermann, K.L.; Isenberg, H.D.; Shamody, H.J. Manual of clinical microbiology. 5.ed. Washington, DC: American Society for Microbiology, p. 1105-1116.

Saúde-Guimarães DA, Faria AR 2007. Substâncias da natureza com atividade anti-Trypanosoma cruzi. Rev Bras Farmacogn 17: 455-465.

Scazzocchio F, Cometa MF, Tomassini L, Palmery M 2001. Antibacterial activity of Hydrastis canadensis extract and its major isolated alkaloids. Planta Med 67: 561-564.

Silveira CS, Pessanha CM, Lourenço MCS, Neves Júnior I, Menezes FS, Kaplan MAC 2005. Atividade antimicrobiana dos frutos de Syagrus oleracea e Mauritia vinifera. Rev Bras Farmacogn 15: 143-148.

Simié A, Sokovic M, Ristic M, Grujic-Jovanovic S, Vukojevic J, Marin P 2004. The chemical composition of some 
Lauraceae essential oils and their antifungal activities. Phytother Res 18: 713-717.

Springfield EP, Amabeoku G, Weitz F, Mabusela W, Johnson Q 2003. An assessment of two Carpobrotus species extracts as potential antimicrobial agents. Phytomedicine 10: 434-439.

Tadeg H, Mohammed E, Asres K, Gebre-Marian T 2005. Antimicrobial activities of some selected traditional Ethiopian medicinal plants used in treatment of skin disorders. J Ethnopharmacol 100: 168-175.

Voravuthikunchai S, Lortheeranuwat A, Jeeju W, Sririrak T, Phongpaichit S, Supawita T 2004. Effective medicinal plants against enterohaemorrhagic Escherichia coli. J Ethnopharmacol 94: 49-54.

Zgoda JR, Porter JR 2001. A convenient microdilution method for screening natural products against bacteria and fungi. Pharm Biol 39: 221-225. 